\section{Chromatin and RNAi factors protect the C. elegans germline against repetitive sequences}

\author{
Valérie J.P. Robert, ${ }^{1}$ Titia Sijen, \\ Josien van Wolfswinkel, and \\ Ronald H.A. Plasterk ${ }^{2}$
}

Hubrecht Laboratory, 3584 CT Utrecht, The Netherlands

Protection of genomes against invasion by repetitive sequences, such as transposons, viruses, and repetitive transgenes, involves strong and selective silencing of these sequences. During silencing of repetitive transgenes, a trans effect ("cosuppression") occurs that results in silencing of cognate endogenous genes. Here we report RNA interference (RNAi) screens performed to catalog genes required for cosuppression in the Caenorhabditis elegans germline. We find factors with a putative role in chromatin remodeling and factors involved in RNAi. Together with molecular data also presented in this study, these results suggest that in C. elegans repetitive sequences trigger transcriptional gene silencing using RNAi and chromatin factors.

Supplemental material is available at http://www.genesdev.org.

Received November 29, 2004; revised version accepted February 8, 2005.

The Caenorhabditis elegans genome is able to repress, in the germline, expression of multicopy transgenes and natural transposable elements. For example, transgenes introduced by microinjection in the germline are maintained as an extrachromosomal heritable array consisting of several hundred copies of the injected DNA (Stinchcomb et al. 1985; Mello et al. 1991). Those arrays are quickly silenced in the germline by a process referred to as "transgene silencing". Moreover, if the repetitive DNA is similar to sequences of a germline-expressed gene, then this endogenous locus is also repressed (Jones and Schedl 1995; Gaudet et al. 1996; Dernburg et al. 2000; Ketting and Plasterk 2000). This array-induced silencing is known as "cosuppression" and typically phenocopies a loss-of-function mutation of the targeted gene.

Transgene silencing seems to include transcriptional repression. In immunostaining experiments, a silenced array is detected using a heterochromatin-specific antibody (against histone H3 methylated on Lys 9), while

[Keywords: RNAi; cosuppression; repetitive sequences; transcriptional gene silencing; heterochromatin; C. elegans]

${ }^{1}$ Present address: Ecole Normale Supérieure, INSERM U497, 46 Rue D'Ulm, 75005 Paris, France

2 Corresponding author.

E-MAIL plasterk@niob.knaw.nl; FAX 31-30-251-6554.

Article published online ahead of print. Article and publication date are at http://www.genesdev.org/cgi/doi/10.1101/gad.332305. this array is not detected with an antibody specific for open chromatin (against histone H3 methylated on Lys 4) (Kelly et al. 2002). Genes involved in this process have been identified (Kelly and Fire 1998; Jedrusik and Schulze 2001, 2003; Couteau et al. 2002) and some, such as mes-2, mes-6, his-24, and hpl-2 (encoding homologs of Enhancer of Zeste, Extra sex combs, histone H1.1, and $\mathrm{HP1}$, respectively), are thought to play a direct role in transcriptional regulation. Interestingly, it has been recently proposed (Fong et al. 2002) that mes-2 and mes-6, together with mes-3 and mes-4, participate in X-chromosome silencing in the germline.

Some genes required for cosuppression have previously been identified (Dernburg et al. 2000; Ketting and Plasterk 2000; Vastenhouw et al. 2003). They are all also involved in two post-transcriptional gene-silencing (PTGS) processes: transposon silencing and RNA interference (RNAi). RNAi is induced by double-stranded RNA (dsRNA) molecules (Fire et al. 1998) that are cleaved by the RNaseIII-related enzyme Dicer (Bernstein et al. 2001) into short interfering RNA (siRNA) duplexes of 21-23 bp (Zamore et al. 2000). Subsequently, siRNAs are incorporated into ribonucleoprotein complexes that guide the specific cleavage of cognate mRNAs (for review, see Tijsterman et al. 2002). Both transposonderived dsRNA and active siRNAs have been detected in C. elegans strains where transposons are silenced in the germline, pointing to strong mechanistic similarities between RNAi and transposon silencing (Sijen and Plasterk 2003).

Previous studies (Dernburg et al. 2000; Ketting and Plasterk 2000) suggest that an unidentified RNA mediator is required to either establish or maintain cosuppression, but the mechanism of cosuppression is still unknown. To investigate cosuppression in C. elegans, we constructed a strain in which a single copy of a germlineexpressed reporter gene is cosuppressed by a repetitive transgene. Like RNAi, cosuppression may involve genes essential for germline development; therefore we reasoned that an important number of genes required for cosuppression could be essential and consequently difficult to identify by classical genetic approaches. We decided to use RNAi, which was previously demonstrated to be a valuable tool to identify essential genes and genes involved in cosuppression (Vastenhouw et al. 2003). We found 59 novel cde (cosuppression defective) genes. Thirteen of the identified cde genes are implicated in transcriptional repression or chromatin structure, and 15 are involved in RNA metabolism. Out of seven tested, we found four cde genes to be also involved in RNAi. These results, together with molecular data also reported in this study, suggest that in C. elegans cosuppression is a complex RNAi-related phenomenon involving both transcriptional and post-transcriptional regulation events.

\section{Results and Discussion \\ Generation of fertile cosuppressed C. elegans lines and requirements to establish cosuppression}

In C. elegans, most of the germline-expressed genes are essential for developmental processes. Because cosuppression phenocopies a loss-of-function mutation of the 
targeted gene (Dernburg et al. 2000; Ketting and Plasterk 2000), cosuppressed lines are often sterile or poorly fertile. To study cosuppression, we established stable, viable cosuppressed lines, using a single-copy integrated transgene expressing a $g f p::$ histone $2 B(g f p:: H 2 B)$ fusion from the germline-specific pie-1 promoter as a marker gene. From AZ212 (Praitis et al. 2001), a transgenic line homozygous for this pie-1::gfp::H2B transgene (Fig. 1A), we derived various lines carrying repetitive arrays of a complete or a truncated $(\Delta) g f p$ gene (Figs. 1B,D, 3A [below]; Supplementary Table S1; Supplementary Fig. S1). We found that pie-1::gfp::H2B could be cosuppressed with the same requirements previously reported for cosuppression of a C. elegans endogenous gene (Dernburg et al. 2000; Ketting and Plasterk 2000). For instance, pie-1::gfp::H2B was silenced in the presence of arrays containing repetitive copies of either complete or truncated $g f p$ sequences fused to the upstream (promotercontaining) regions of the ubiquitously expressed genes dpy-30 or him-14 (Fig. 1B; Supplementary Table S1A). This silencing could be released in an rde-2 (pk716) (Tops et al. 2005) genetic background (Fig. 1B) or after RNAi-mediated knock-down of mut-16 (Vastenhouw et al. 2003).

RNase protection assays (RPAs) (Fig. 1C) using a probe recognizing only the full-length $g f p$ mRNA expressed

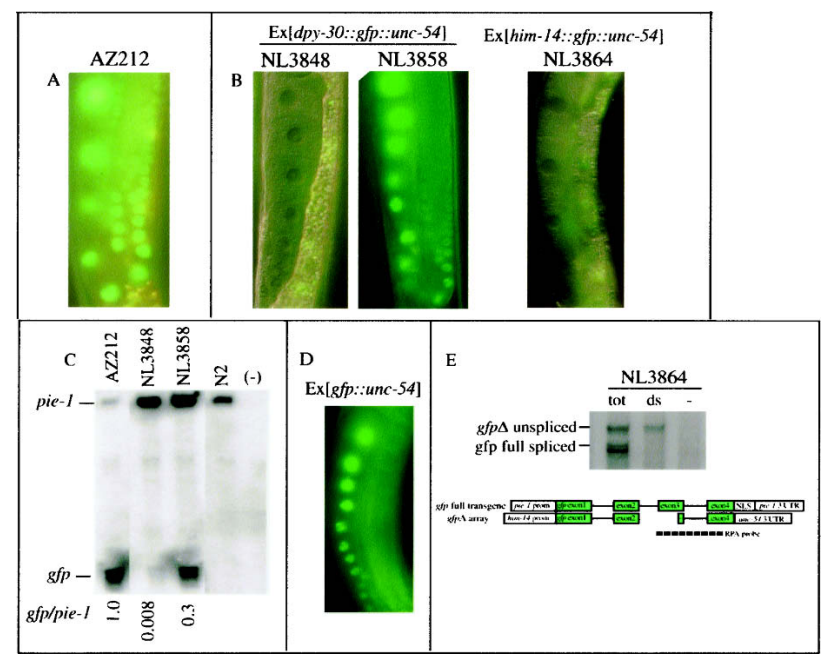

Figure 1. Germline cosuppression of pie-1::gfp::H2B. (A) Germline GFP expression in AZ212, a strain homozygous for pie$1:: g f p:: H 2 B$. A lineup of oocytes expressing GFP localized in their nuclei is shown. (B) Cosuppression is induced in lines NL3847 and NL3864 that respectively contain $d p y-30:: g f p \Delta::$ unc-54 and him$14:: g f p \Delta:: u n c-54$ integrated arrays; lineups of oocytes that no longer express the GFP are shown. Cosuppression induced by the dpy$30:: g f p \Delta::$ unc-54 array (line NL3848) is released in an rde-2 (pk716) background (strain NL3858). (C) In cosuppressed lines gfp mRNA levels are strongly reduced as apparent from RPAs using a probe specific for the full-length $g f p$ mRNA. For control on RNA loading and developmental stage, a pie-1-specific probe was added in each RPA and the ratio of gfp to pie-1 mRNA was determined. The reference strain N2 and a yeast tRNA (-) were used as negative controls. $(D)$ The pie-1::gfp::H2B locus is not silenced by an array of promoterless $g f p$ copies. $(E)$ RPAs detect dsRNA molecules in cosuppressed lines. Samples were pretreated to contain total RNA (tot), only dsRNA (ds), or no RNA (-). The RPA probe (of anti-sense polarity) discriminates unspliced and spliced $g f p \Delta$ or $g f p$ full sequences. Protected fragments in the dsRNA lane correspond mainly to the unspliced form of the $g f p \Delta$ transcripts. Similar results were obtained with NL3847 and NL3848 (data not shown).

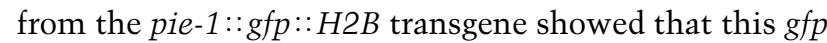
mRNA is present in the nonsilenced line AZ212, largely absent in the silenced line NL3848, and present again in an rde-2 (pk716) genetic background (strain NL3858). Interestingly, in the rde-2 background, gfp mRNA levels are not restored to the $g f p$ mRNA levels observed in AZ212. This result suggests that cosuppression is a complex process, which may require besides the RNAi machinery other pathways to induce efficient silencing.

\section{dsRNA is present in cosuppressed lines}

Silencing of pie-1::gfp::H2B is dependent on the expression of the repetitive $g f p$ sequences since an array of promoterless $g f p$ sequences does not induce cosuppression (Fig. 1D; Supplementary Table S1B). This observation supports the hypothesis that cosuppression is triggered by an RNA signal (Dernburg et al. 2000; Ketting and Plasterk 2000).

Because gene silencing processes can be induced by dsRNA molecules and because arrays are concatemers of sequences that are likely to be both tandemly and inversely oriented, we hypothesized that the RNA signal that induces cosuppression is dsRNA. Using RPAs, we analyzed various cosuppressed lines for the presence of dsRNA (Fig. 1E; data not shown). A probe was used that can discriminate RNAs derived from pie-1::gfp::H2B and RNAs generated from the repetitive $g f p \Delta$ sequences. In samples pretreated to contain only dsRNA, we detect mainly a protected fragment corresponding to the unspliced RNA derived from the repetitive $g f p \Delta$ sequences. This result shows that dsRNAs are produced from the arrays, presumably via pairing of unspliced sense and anti-sense transcripts, these former being potentially generated from fortuitous transcription in the array (e.g., read-through transcription). We also asked whether those dsRNA molecules could be processed into siRNAs. Using RPA, we have not detected $g f p$-specific siRNAs in cosuppressed lines NL3847, NL3848, NL3864, and NL3882 (see Materials and Methods; data not shown). We further investigated this question with RNAi experiments targeting the essential gene $d c r-1$, which encodes the C. elegans Dicer enzyme required to produce siRNA in RNAi. RNAi knock-down of $d c r-1$ results in a strongly disorganized germline in which it is difficult to localize nuclei and detect GFP expression, but re-expression of cosuppressed pie-1::gfp::H2B was observed in two out of six NL3847 animals whereas no re-expression was observed in nine NL3864 animals (Supplementary Table S2). These results suggest that Dicer action is required for cosuppression; since we cannot detect the presumed products of Dicer, $g f p$-specific siRNAs, we conclude that these are probably produced during cosuppression but not at a detectable level.

\section{RNAi screens identify 59 novel cde genes}

To identify cde genes, we performed a genome-wide RNAi screen. 16,787 genes were individually targeted in cosuppressed line NL3847 and GFP re-expression was monitored after one generation of feeding Escherichia coli expressing dsRNA. One-hundred-and-twenty cde candidate genes were identified. Because expression of the repetitive sequences is essential to induce cosuppression (Dernburg et al. 2000; Ketting and Plasterk 2000; this study), we assumed that some of the identified can- 
didates may be involved in the control of the $d p y-30$ promoter instead of being true cde genes. Therefore, the candidates were retested using line NL3864, in which cosuppression of pie-1::gfp::H2B is induced by an him$14:: g f p \Delta:: u n c-54$ array. Fifty-nine candidates remained as putative cde genes (Fig. 2A). Forty-nine nonessential cde genes were retested by feeding the corresponding dsRNA to a C. elegans strain (UF5) exhibiting a partial sterility as a result of cosuppression of the gene ppk-1 (see Materials and Methods). Restoration of normal fertility was observed for 40 of the tested genes. We consider those 40 genes and the 10 genes involved in nematode fertility as cde genes.

All but one (mut-16; Vastenhouw et al. 2003) of the genes identified in this screen have not so far been reported to be involved in cosuppression. Based on the biological processes that they are predicted to be involved in (as described by WormBase, http://www.wormbase.org), they fall into four functional classes (Table 1; Supplementary S3). Class I groups 12 cde genes with no predicted function. Class II includes 19 cde genes involved in processes like energy metabolism, signaling, protein metabolism, and chromosome segregation. Eleven cde genes are involved in RNA metabolism and are placed into Class III. They include (1) two RNA splicing and processing factors; (2) K10D2.3 and rde-3 (Chen et al. 2005), two members of the polymerase $\beta$ nucleotidyl-

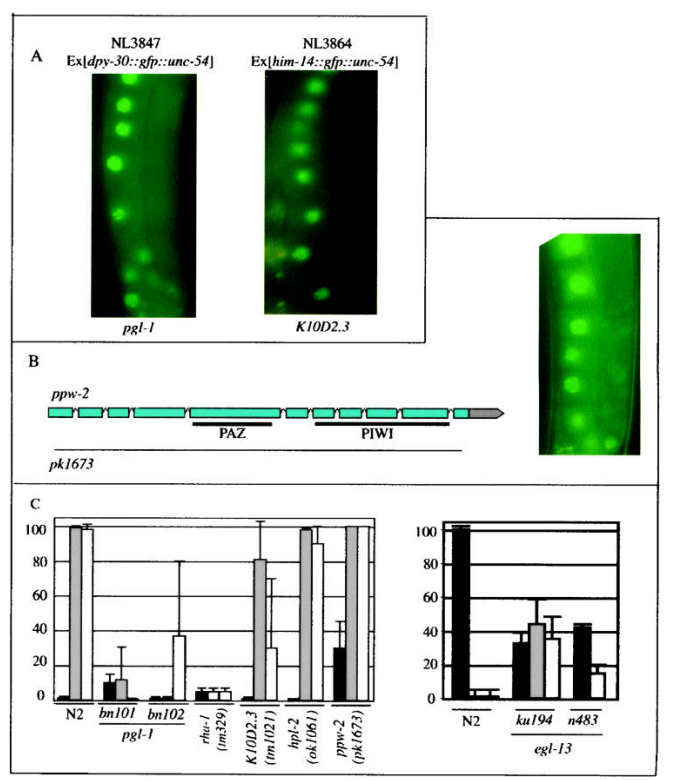

Figure 2. Identification of $c$ de genes and their involvement in other silencing processes. $(A)$ Re-expression of GFP upon feeding strain NL3847 or NL3864 with food expressing dsRNA targeting cde gene pgl-1 or K10D2.3, respectively. (B) pk1673, a deletion allele of $p p w$ 2 , removes most of the coding sequences (dashed line; see Supplemental Material)-including the conserved domains PAZ and PIWI (plain lines) - and exhibits a cde phenotype when genetically combined to pie-1::gfp::H2B in the presence of a him-14::gfp $::$ unc-54 array. $(C)$ The cde genes pgl-1, rha-1, egl-13, and K10D2.3 are involved in RNAi. Deletion alleles for pgl-1, egl-13, rha-1, ppw-2, K10D2.3, and hpl-2 (see Supplemental Material) were tested for RNAi competence on food targeting the germline-expressed genes pos-1 (gray bars) and par-1 (white bars). Wild-type OP50 bacteria were used as a negative control (black bars). For pgl-1, rha-1, K1OD2.3, hpl-2, and ppw-2, the percentage of dead embryos was estimated (left panel); for egl-13, which is egg-laying deficient, the brood size of single animals was estimated (right panel). transferase superfamily, which includes polyA polymerases and 2' -5 ' oligoadenylate synthetase; (3) Y48B6A.3, a 5'-3' exoribonuclease; (4) one Argonaute protein; and (5) five RNA-binding proteins. Finally, seven cde genes go into Class IV comprising two putative chromatin genes and five DNA-binding factors. These include the chromo domain-containing protein T12E12.2, the SET domain protein, MES-4, and the transcription factors, HMG-5 and EGL-13.

Previous studies (Vastenhouw et al. 2003; N. Vastenhouw, S. Fischer, K. Thijssen, and R. Plasterk, pers. comm.) had identified five cde genes (Class 0 in Table 1 and Supplementary Table S3), of which only mut-16 was recovered as a cde gene in this genome-wide approach. We performed a second RNAi screen with a specific set of genes (Supplementary Table S2) preselected because they held a high degree of sequence similarity either to candidates identified in the genome-wide screen or to genes known to be involved in silencing processes in $C$. elegans or other organisms. With this smaller set of genes we could perform a more detailed analysis than was feasible in the high-throughput setup (e.g., we monitored GFP expression over more than one generation, and used Nomarski optics instead of a dissecting microscope). One-hundred-and-eighty-six candidates were tested under these conditions. Ten additional cde genes were identified; they are (1) a third member of the polymerase $\beta$ nucleotidyltransferase superfamily, a third Argonaute protein, the conserved RNA helicase rha-1, and a dsRNA-binding-containing protein (all involved in RNA metabolism [Class III]); and (2) six Class IV proteins, including hpl-2 and two other chromo domain proteins, two additional SET domain proteins, and one HMG box protein.

In total, these two approaches identified 59 novel cde genes.

\section{Cde genes and their roles in related silencing processes}

Cosuppression, RNAi, transposon silencing, and miRNA processing and function have been shown to be related processes (Tabara et al. 1999; Dernburg et al. 2000; Ketting and Plasterk 2000; Grishok et al. 2001; Vastenhouw et al. 2003). Having recovered a large set of genes involved in cosuppression, we now asked whether some of the identified cde genes could be involved in other silencing processes.

First, we assayed the 59 cde genes for reversion of a Tc1 transposon insertion in a muscle gene, unc-22 (Vastenhouw et al. 2003). Animals homozygous for unc22::Tc1 exhibit a Twitcher phenotype and we scored their progeny for wild-type moving animals in which Tc1 has excised. Such animals were observed after targeting the five previously characterized mut genes also identified as cde genes (Class 0 in Table 1 and Supplementary Table S3) and K10D2.3 (Class III in Table 1 and Supplementary Table S3). Second, we tested whether putative $c d e$ genes could be involved in miRNA processing and function using a transgenic line expressing $\mathrm{LacZ}$ in the seam cells, under the translational control of let-7 (Denli et al. 2004). The 59 cde genes were tested and we identified (1) the Class II-cde gene $k b p-3,(2)$ the premRNA splicing factor M03F8.3, and (3) the putative exoribonuclease Y48B6A.3 as regulators of the col10::LacZ::lin-41 3'UTR reporter construct (data not shown). Interestingly, AtXrn4, an Arabidopsis Y48B6A.3- 
Table 1. Classification of cde genes

\begin{tabular}{|c|c|c|}
\hline Class & Subclass & Genes \\
\hline \multirow[t]{4}{*}{ 0: Known cde genes } & PolyQ domain & mut-16 \\
\hline & PAZ/PIWI domain & $p p w-2$ \\
\hline & RNA helicase & T05E8.3 \\
\hline & Unknown & C28A5.1; C28A5.2 \\
\hline \multirow[t]{2}{*}{ I: Undetermined process } & Conserved domains & C18G1.7; R08D7.2 \\
\hline & No domain & $\begin{array}{l}\text { F38A5.10; gfi-4; T09E8.1; B0302.5; F35C8.8; T23B5.3; T19C4.5; } \\
\quad \text { Y12A6A.1; smu-2; C26F1.3 }\end{array}$ \\
\hline \multirow[t]{6}{*}{ II: Various processes } & Metabolism & T22D1.3; T07A9.8; Y40B10A.6; C24F3.4; vha-7 \\
\hline & Signaling & srh-75; H25K10.6; R11G1.1; add-1; F14H3.12; T21C9.6 \\
\hline & Ribosomal subunit & C37A2.7; Y43F8C.8 \\
\hline & Nuclear import & ima-1; ima-3 \\
\hline & Ubiq. dep. prot. degr. & H19N07.2 \\
\hline & Chromosome segr. & kbp-1; kbp-3; sas-4 \\
\hline \multirow{10}{*}{$\begin{array}{l}\text { III: RNA and protein } \\
\text { metabolism }\end{array}$} & pre-mRNA splic. & M03F8.3 \\
\hline & RNA processing & $1 s m-7$ \\
\hline & Nucleotidyltransferase & K10D2.3; rde-3; F43E2.1 \\
\hline & $5 '-3^{\prime}$ exoribonuclease & Y48B6A.3 \\
\hline & RNA helicase & rha-1 \\
\hline & PAZ/PIWI domain & F20D12.1; C14B1.7 \\
\hline & RGG box & pgl-1 \\
\hline & RRM domain & K08F4.2; R119.7; К07H8.10 \\
\hline & Tudor domain & $F 22 D 6.6$ \\
\hline & Dsrb domain & F55A4.4 \\
\hline \multirow{5}{*}{$\begin{array}{l}\text { IV: Chromatin structure } \\
\text { and transcription }\end{array}$} & Chromo domain & T12E12.2; mrg-1; T09A5.8 \\
\hline & Chromo shadow & $h p l-2$ \\
\hline & SET domain & mes-4; C43E11.3; C15H11.5 \\
\hline & HMG box & hmg-5; egl-13; W02D9.3 \\
\hline & Zn finger & pqn-2; B0336.3; F35H8.3 \\
\hline
\end{tabular}

related gene, has recently been implicated in RNAi (Gazzani et al. 2004) and miRNA-mediated silencing (Souret et al. 2004).

To address the possible role of some cde-genes in RNAi in the germline, we used (viable) genetic mutants of these genes. Mutants for egl-13 (Hanna-Rose and Han 1999; Cinar et al. 2003) and pgl-1 (Kawasaki et al. 1998) were available in the literature; genomic deletions were described in databases for rha-1, K10D2.3, and hpl-2 (see Supplemental Material), and we screened a deletion library for a knock-out of $p p w-2$ (Fig. 2B). These mutants were studied for their RNAi competence. Interestingly, mutants for egl-13, pgl-1, and rha-1 exhibited strong resistance to RNAi when fed with foods targeting the germline-specific genes pos-1 and par-1 (Fig. 2C). The K10D2.3 mutant showed partial resistance to germline RNAi (Fig. 2C, par-1 dsRNA-feeding). Finally, hpl-2 and $p p w-2$ mutants are still sensitive to RNAi, which suggests that besides RNAi, RNAi-independent pathways have a role in cosuppression.

\section{Transcriptional silencing in cosuppression}

Extrachromosomal arrays are inherited as mosaics (Stinchcomb et al. 1985; Mello et al. 1991). We analyzed the progeny of animals in which pie-1::gfp::H2B is silenced by a dpy-30::gfp::unc-54 array. Re-expression of pie-1::gfp::H2B was not observed in either the F1 progeny that inherited the array (data not shown) or in the animals that did not inherit the array (F1, Fig. 3A). GFP fluorescence started to be faintly expressed in the progeny of F1 not carrying the array (F2, Fig. 3A) and two additional generations were necessary to observe full reexpression of pie-1::gfp::H2B. This observation was reproduced with several cosuppressed lines (data not shown). Long-term RNAi-induced PTGS has not been reported in C. elegans and what we observe for cosuppression suggests that a different kind of regulation than PTGS occurs at the cosuppressed endogenous locus.

RPAs (Fig. 1C) indicated that cosuppression affects the levels of mRNAs generated by pie-1::gfp:H2B. To further investigate this aspect, we analyzed the ratio of spliced to unspliced $g f p$ mRNA from the pie-1::gfp::H2B gene in cosuppressed and re-expressed lines. If in the re-expressed lines transcriptional silencing is relieved, the transcription rates should increase and the ratio of spliced to unspliced $g f p$ mRNA should remain the same. If, on the other hand, post-transcriptional silencing is relieved, the ratio of spliced to unspliced $g f p$ mRNA should increase, because post-transcriptional silencing specifically targets cytoplasmic, spliced mRNAs. Re-expression was obtained either by crossing the $g f p$ cosuppression system in an $r d e-2(p k 716)$ background or by feeding cosuppressed worms with bacteria containing dsRNA targeting mut-16, a gene involved in cosuppression. RPAs (Fig. 3B) show that the ratio of spliced to unspliced $g f p$ mRNA is unaltered in re-expressed lines, implying that cosuppression involves transcriptional silencing of pie-1::gfp::H2B.

In summary, we have demonstrated that cosuppression (1) is a dsRNA-induced RNAi-mediated silencing; (2) requires genes involved in chromatin structure, transcriptional regulation, and post-transcriptional regulation; and (3) induces transcriptional repression at least at 


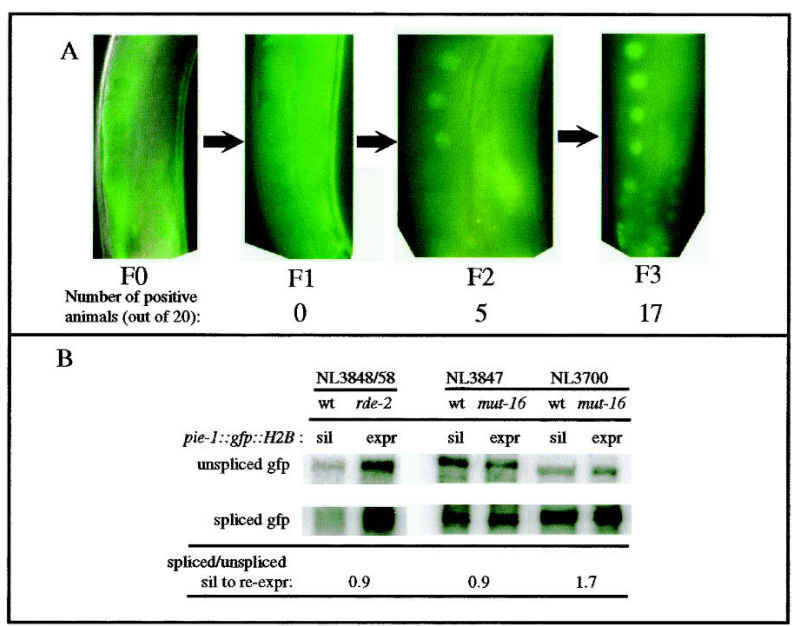

Figure 3. Analysis of release of cosuppression. (A) GFP re-expression was studied in a line in which pie-1::gfp::H2B is cosuppressed by an extrachromosomal array of repetitive $d p y-30:: g f p::$ unc-54 sequences (including a rol6 marker) after loss of the extrachromosomal array. The nonroller progeny (F1, F2, and F3) of a roller parent (F0) exhibit a progressive re-expression of pie-1::gfp::H2B. The number of positive animals out of 20 examined is indicated for each generation. $(B)$ Release of cosuppression involves release of transcriptional gene silencing. The ratio of spliced to unspliced $g f p$ transcripts expressed from pie-1::gfp::H2B was compared in silenced and re-expressed states either after crossing the cosuppressed line NL3848 in an rde-2(pk716) background (NL3858) or after feeding cosuppressed line NL3847 (results not shown for NL3848 and NL3864) dsRNA-food targeting the mut/cde/rde gene mut-16. The spliced/unspliced ratio remains the same in cosuppressed and reexpressed states but increases upon re-expression of pk1660 (NL3700) that is post-transcriptionally silenced by natural Tc1 siRNA (Sijen and Plasterk, 2003). Similar results were obtained after feeding NL3848 and NL3864 with dsRNA food targeting mut-16.

the endogenous locus. In diverse organisms such as plants, yeast, flies, and humans (Matzke et al. 2001; Hall et al. 2002, 2003; Volpe et al. 2002; Lippman et al. 2004; Noma et al. 2004; Pal-Bhadra et al. 2004; Sugiyama et al. 2005), RNA-mediated transcriptional silencing has been documented and appears to share components of the PTGS/RNAi route. The relationship between transcriptional gene silencing (presumably at the chromatin level) and RNAi has not yet been clearly established in C. elegans. The results presented in this study provide evidence that such a relationship also exists in C. elegans and that these regulatory processes are essential to protect the germline against repetitive sequences.

\section{Materials and methods}

Strains and alleles

Plasmids (pPD93.97:myo-3::gfp, pPD93.48:unc-54::gfp, pPD118.26:hsp16.2::gfp [kind gifts from Dr A. Fire, Stanford University School of Medicine, Stanford, CA], or pJL53.1:hsp-16.48::gfp [kind gift from Dr J.-L. Besserreau, Ecole Normale Supérieure, Paris, France]) and PCR products (dpy-30::gfp::unc-54, dpy-30::gfps::unc-54, him-14::gfp::unc-54, and him-14::gfps::unc-54? were microinjected, together with the dominant marker rol-6(su1006), in the germline of AZ212. The PCR products were generated as described in Vastenhouw et al. (2003); the him-14 promoter was PCR amplified from N2 genomic DNA using primers CTTCCATCCGGAAAAATCCAACGC and TCCCGGGGATCCTCTA GAGTCCATCTACAAAAAGGGATGGGATTG. The complete $g f p$ product was PCR amplified from plasmid pPD95-77 using primers GACTCTAGAGGATCCCCGGGA and GAGCCTCAAACCCAAACC
TTC. Primers GAGCGCTTCGAGTTGTTTGCGG and GCATCGTGC TCATCAATACTTGTG were used to generate the him-14::gfp::unc-54 and him-14::gfps::unc-54 PCR products. Subsequent X-ray-induced extrachromosomal array integrations (Mello et al. 1991) were carried out to generate lines NL3847 \{unc-119(ed3) ruIs32[pAZ132:pie-1::gfp::H2B] III pkIs1600[dpy-30::gfps::unc-54 pRF4(rol-6(su1006))] I\}, NL3848 \{unc119(ed3) ruIs32[pAZ132:pie-1::gfp::H2B] III pkIs1598[dpy-30::gfps::unc54pRF4(rol-6(su1006))]\}, and NL3864 \{unc-119(ed3) ruIs32[pAZ132:pie$1:: g f p:: H 2 B]$ III pkIs1622[him-14::gfps::unc54 pRF4(rol-6(su1006)]\}. NL3858 was obtained by introduction of ruIs32 and pkIs1598 in an rde2(pk716) background and NL3882 was obtained by introduction of ruIs32 and pkIs1600 in an rrf-3(pk1426) background.

A description of the other strains used in this study is provided in the Supplemental Material.

The strains were maintained and the genetic experiments were performed at $20^{\circ} \mathrm{C}$.

RNA analyses

RNA isolation and RPAs were performed as described in Sijen et al. (2001) and Sijen and Plasterk (2003). To select for dsRNA, RNA was pretreated with RNaseA (20 $\mu \mathrm{g}$ RNaseA/mL; Boehringer) for $30 \mathrm{~min}$ at $30^{\circ} \mathrm{C}$ in the presence of $0.3 \mathrm{M} \mathrm{NaCl}$, which was followed by protease $\mathrm{K}$ treatment and phenol/chloroform extraction. The probes used for $g f p$ were gfp2 (418-719) (numbered from ATG) and gfpdel (378-536) in antisense polarity. Quantification of protected fragments (RPAs) was performed using ImageQuant software.

\section{RNAi screens}

For the genome-wide screen, 6-cm RNAi plates with NGM supplemented with $0.8 \mathrm{mM}$ IPTG and $50 \mu \mathrm{g} / \mathrm{mL}$ ampicillin were inoculated with overnight bacterial cultures of an RNAi library (Kamath et al. 2003). The expression of dsRNA was induced overnight at room temperature before L4 NL3847 animals were singled on these plates. The animals were grown $1 \mathrm{wk}$ at $20^{\circ} \mathrm{C}$ and scored for germline expression of GFP. A similar strategy was used for the preselected approach, except that both lines NL3847 and NL3864 were scored for two to three generations after transfer on fresh RNAi plates.

\section{Acknowledgments}

We are grateful to Tamara Chelsa and David Weinkove for the gift of strain UF5 and for sharing data before publication. Some of the C. elegans strains used in this study were provided by the Caenorhabditis Genetic Center and the Japanese National BioResources Project. We thank Anja Bathoorn for technical assistance. We thank Brandon Aason, Robin May, Marcel Tijsterman, and René Ketting for the critical reading of this manuscript.

\section{References}

Bernstein, E., Caudy, A.A., Hammond, S.M., and Hannon, G.J. 2001. Role for a bidentate ribonuclease in the initiation step of RNA interference. Nature 409: 363-366.

Chen, C., Simard, M.J., Tabara, H., Brownell, D.R., McCollough, J.A., and Mello, C.C. 2005. A member of the polymerase $\beta$ nucleotidyltransferase superfamily is required for RNA interference in C. elegans. Curr. Biol. 15: 378-383.

Cinar, H.N., Richards, K.L., Oommen, K.S., and Newman, A.P. 2003. The EGL-13 SOX domain transcription factor affects the uterine pi cell lineages in Caenorhabditis elegans. Genetics 165: 1623-1628.

Couteau, F., Guerry, F., Muller, F., and Palladino, F. 2002. A heterochromatin protein 1 homologue in Caenorhabditis elegans acts in germline and vulval development. EMBO Rep. 3: 235-241.

Denli, A.M., Tops, B.B., Plasterk, R.H., Ketting, R.F., and Hannon, G.J. 2004. Processing of primary microRNAs by the Microprocessor complex. Nature 432: 231-235.

Dernburg, A.F., Zalevsky, J., Colaiacovo, M.P., and Villeneuve, A.M. 2000. Transgene-mediated cosuppression in the C. elegans germ line. Genes \& Dev. 14: 1578-1583.

Dudley, N.R., Labbe, J.C., and Goldstein, B. 2002. Using RNA interference to identify genes required for RNA interference. Proc. Natl. Acad. Sci. 99: 4191-4196.

Fire, A., Xu, S., Montgomery, M.K., Kostas, S.A., Driver, S.E., and Mello, 
C.C. 1998. Potent and specific genetic interference by doublestranded RNA in Caenorhabditis elegans. Nature 391: 806-811.

Fong, Y., Bender, L., Wang, W., and Strome, S. 2002. Regulation of the different chromatin states of autosomes and $\mathrm{X}$ chromosomes in the germ line of C. elegans. Science 296: 2235-2238.

Gaudet, J., VanderElst, I., and Spence, A.M. 1996. Post-transcriptional regulation of sex determination in Caenorhabditis elegans: Widespread expression of the sex-determining gene fem-1 in both sexes. Mol. Biol. Cell 7: 1107-1121.

Gazzani, S., Lawrenson, T., Woodward, C., Headon, D., and Sablowski, R. 2004. A link between mRNA turnover and RNA interference in Arabidopsis. Science 306: 1046-1048.

Grishok, A., Pasquinelli, A.E., Conte, D., Li, N., Parrish, S., Ha, I., Baillie, D.L., Fire, A., Ruvkun, G., and Mello, C.C. 2001. Genes and mechanisms related to RNA interference regulate expression of the small temporal RNAs that control C. elegans developmental timing. Cell 106: $23-34$

Hall, I.M., Shankaranarayana, G.D., Noma, K., Ayoub, N., Cohen, A., and Grewal, S.I. 2002. Establishment and maintenance of a heterochromatin domain. Science 297: 2232-2237.

Hall, I.M., Noma, K., and Grewal, S.I. 2003. RNA interference machinery regulates chromosome dynamics during mitosis and meiosis in fission yeast. Proc. Nat1. Acad. Sci. 100: 193-198.

Hanna-Rose, W. and Han, M. 1999. COG-2, a sox domain protein necessary for establishing a functional vulval-uterine connection in Caenorhabditis elegans. Development 126: 169-179.

Jedrusik, M.A. and Schulze, E. 2001. A single histone H1 isoform (H1.1) is essential for chromatin silencing and germline development in Caenorhabditis elegans. Development 128: 1069-1080.

- 2003. Telomeric position effect variegation in Saccharomyces cerevisiae by Caenorhabditis elegans linker histones suggests a mechanistic connection between germ line and telomeric silencing. Mol. Cell. Biol. 23: 3681-3691.

Jones, A.R. and Schedl, T. 1995. Mutations in gld-1, a female germ cellspecific tumor suppressor gene in Caenorhabditis elegans, affect a conserved domain also found in Src-associated protein Sam68. Genes \& Dev. 9: 1491-1504.

Kamath, R.S., Fraser, A.G., Dong, Y., Poulin, G., Durbin, R., Gotta, M., Kanapin, A., Le Bot, N., Moreno, S., Sohrmann, M., et al. 2003. Systematic functional analysis of the Caenorhabditis elegans genome using RNAi. Nature 421: 231-237.

Kawasaki, I., Shim, Y.H., Kirchner, J., Kaminker, J., Wood, W.B., and Strome, S. 1998. PGL-1, a predicted RNA-binding component of germ granules, is essential for fertility in C. elegans. Cell 94: 635-645.

Kelly, W.G. and Fire, A. 1998. Chromatin silencing and the maintenance of a functional germline in Caenorhabditis elegans. Development 125: 2451-2456.

Kelly, W.G., Schaner, C.E., Dernburg, A.F., Lee, M.H., Kim, S.K., Villeneuve, A.M., and Reinke, V. 2002. X-chromosome silencing in the germline of C. elegans. Development 129: 479-492.

Ketting, R.F. and Plasterk, R.H. 2000. A genetic link between co-suppression and RNA interference in C. elegans. Nature 404: 296-298.

Lippman, Z., Gendrel, A.V., Black, M., Vaughn, M.W., Dedhia, N., McCombie, W.R., Lavine, K., Mittal, V., May, B., Kasschau, K.D., et al. 2004. Role of transposable elements in heterochromatin and epigenetic control. Nature 430: 471-476.

Matzke, M.A., Matzke, A.J., Pruss, G.J., and Vance, V.B. 2001. RNAbased silencing strategies in plants. Curr. Opin. Genet. Dev. 11: 221227.

Mello, C.C., Kramer, J.M., Stinchcomb, D., and Ambros, V. 1991. Efficient gene transfer in C. elegans: Extrachromosomal maintenance and integration of transforming sequences. EMBO J. 10: 3959-3970.

Noma, K., Sugiyama, T., Cam, H., Verdel, A., Zofall, M., Jia, S., Moazed, D., and Grewal, S.I. 2004. RITS acts in cis to promote RNA interference-mediated transcriptional and post-transcriptional silencing. Nat. Genet. 36: 1174-1180.

Pal-Bhadra, M., Leibovitch, B.A., Gandhi, S.G., Rao, M., Bhadra, U., Birchler, J.A., and Elgin, S.C. 2004. Heterochromatic silencing and HP1 localization in Drosophila are dependent on the RNAi machinery. Science 303: 669-672.

Praitis, V., Casey, E., Collar, D., and Austin, J. 2001. Creation of low-copy integrated transgenic lines in Caenorhabditis elegans. Genetics 157: 1217-1226.
Sijen, T. and Plasterk, R.H. 2003. Transposon silencing in the Caenorhabditis elegans germ line by natural RNAi. Nature 426: 310314.

Sijen, T., Vijn, I., Rebocho, A., van Blokland, R., Roelofs, D., Mol, J.N.M., and Kooter, J.M. 2001. Transcriptional and posttranscriptional gene silencing are mechanistically related. Curr. Biol. 11: 1-20.

Souret, F.F., Kastenmayer, J.P., and Green, P.J. 2004. AtXRN4 degrades mRNA in Arabidopsis and its substrates include selected miRNA targets. Mol. Cell 15: 173-183.

Stinchcomb, D.T., Shaw, J.E., Carr, S.H., and Hirsh, D. 1985. Extrachromosomal DNA transformation of Caenorhabditis elegans. Mol. Cell. Biol. 5: 3484-3496.

Sugiyama, T., Cam, H., Verdel, A., Moazed, D., and Grewal, S.I. 2005. RNA-dependent RNA polymerase is an essential component of a selfenforcing loop coupling heterochromatin assembly to siRNA production. Proc. Natl. Acad. Sci. 102: 152-157.

Tabara, H., Sarkissian, M., Kelly, W.G., Fleenor, J., Grishok, A., Timmons, L., Fire, A., and Mello, C.C. 1999. The rde-1 gene, RNA interference, and transposon silencing in C. elegans. Cell 99: 123-132.

Tijsterman, M., Ketting, R.F., and Plasterk, R.H. 2002. The genetics of RNA silencing. Annu. Rev. Genet. 36: 489-519.

Tops, B.B., Tabara, H., Sijen, T., Simmer, F., Mello, C.C., Plasterk, R.H., and Ketting, R.F. 2005. RDE-2 interacts with MUT-7 to mediate RNA interference in Caenorhabditis elegans. Nucleic Acids Res. 33: 347355.

Vastenhouw, N.L., Fischer, S.E., Robert, V.J., Thijssen, K.L., Fraser, A.G., Kamath, R.S., Ahringer, J., and Plasterk, R.H. 2003. A genome-wide screen identifies 27 genes involved in transposon silencing in C. elegans. Curr. Biol. 13: 1311-1316.

Volpe, T.A., Kidner, C., Hall, I.M., Teng, G., Grewal, S.I., and Martienssen, R.A. 2002. Regulation of heterochromatic silencing and histone H3 lysine-9 methylation by RNAi. Science 297: 1833-1837.

Zamore, P.D., Tuschl, T., Sharp, P.A., and Bartel, D.P. 2000. RNAi: Double-stranded RNA directs the ATP-dependent cleavage of mRNA at 21 to 23 nucleotide intervals. Cell 101: 25-33. 


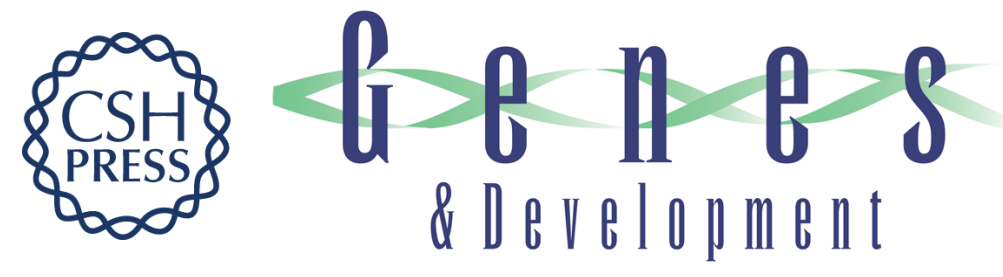

\section{Chromatin and RNAi factors protect the $C$. elegans germline against repetitive sequences}

Valérie J.P. Robert, Titia Sijen, Josien van Wolfswinkel, et al.

Genes Dev. 2005, 19:

Access the most recent version at doi:10.1101/gad.332305

Supplemental http://genesdev.cshlp.org/content/suppl/2005/03/16/gad.332305.DC1
Material

References This article cites 39 articles, 18 of which can be accessed free at: http://genesdev.cshlp.org/content/19/7/782.full.html\#ref-list-1

License

Email Alerting Receive free email alerts when new articles cite this article - sign up in the box at the top Service right corner of the article or click here.

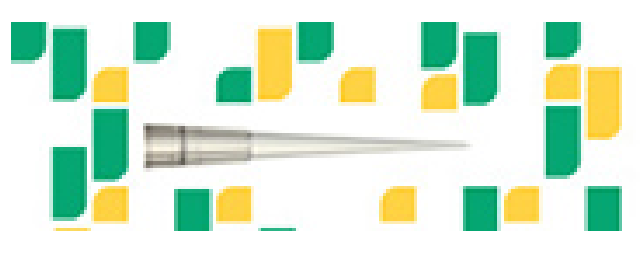

Focused on your science. 